Houtum, L. van, Rijken, M., Heijmans, M., Groenewegen, P. Patient-perceived self-management tasks and support needs of people with chronic illness: generic or disease specific? Annals of Behavioral Medicine: 2014

\begin{tabular}{|l|l|}
\hline $\begin{array}{l}\text { Postprint } \\
\text { Version }\end{array}$ & 1.0 \\
\hline Journal website & http://link.springer.com/article/10.1007\%2Fs12160-014-9649-0 \\
\hline Pubmed link & $\underline{\text { http://www.ncbi.nlm.nih.gov/pubmed/25199663 }}$ \\
\hline DOI & $10.1007 / \mathrm{s} 12160-014-9649-0$ \\
\hline
\end{tabular}

This is a NIVEL certified Post Print, more info at http://www.nivel.eu

\title{
Patient-Perceived Self-Management Tasks and Support Needs of People with Chronic Illness: Generic or Disease Specific?
}

\author{
Lieke van Houtum ${ }^{1}$, Mieke RiJKen ${ }^{1}$, Monique Heijmans ${ }^{1}$ and Peter GroenewegeN ${ }^{1,2}$ \\ (1) Netherlands Institute for Health Services Research (NIVEL), PO Box 1568, 3500 BN \\ Utrecht, Netherlands \\ (2) Department of Sociology and Department of Human Geography, Utrecht University, \\ Utrecht, The Netherlands
}

\begin{abstract}
Background: Self-management is widely accepted as an essential component of chronic care. Nevertheless, little is known about patients' perceptions of selfmanagement.

Purpose: This study aims to explore which self-management tasks and support needs people with chronic illness perceive for themselves, and to establish whether these tasks and support needs are disease specific.

Methods: A nationwide representative sample of 2,064 people with chronic disease filled in the Patient Assessment of Self-management Tasks questionnaire.

Results: Many respondents perceive self-management tasks in the daily management of their condition, although few indicate a need for support. Respondents who feel a need for support in one aspect of self-management are likely to feel a need for support in other aspects as well. Type of disease has a small effect on self-management tasks and even smaller on support needs.

Conclusion: Although the self-management tasks patients perceive may be partly disease specific, self-management support does not necessarily need to be disease specific.

Electronic supplementary material: The online version of this article (doi:10. 1007/s12160-014-9649-0) contains supplementary material, which is available to authorized users.
\end{abstract}

\section{INTRODUCTION}

The prevalence of chronic diseases such as heart disease, chronic obstructive pulmonary disease (COPD), and diabetes type II is increasing worldwide $\left[{ }^{1},{ }^{2}\right]$. In 
Houtum, L. van, Rijken, M., Heijmans, M., Groenewegen, P. Patient-perceived self-managementh tasks and support needs of people with chronic illness: generic or disease specific? Annals of Behavioral Medicine: 2014

2008, $63 \%$ of all deaths were caused by chronic diseases. Good care can help control a chronic disease $\left[{ }^{2}\right]$. As patients are largely responsible for the day-to-day care of their chronic illness, self-management is an essential part of chronic illness care. Self-management involves not only the medical management of a condition but also maintaining, changing and creating new meaningful behaviors or life roles, and coping with the psychosocial consequences of chronic illness $\left[{ }^{3}-{ }^{6}\right]$. Successful selfmanagement can avoid preventable mortality and morbidity, improve the quality of life of individuals and families, and boost economic productivity $\left[^{7}\right]$.

Unfortunately, many people with chronic illness find it difficult to self-manage successfully $\left[{ }^{8},{ }^{9}\right]$. Appropriate support is therefore very important. During the last decades, numerous programs to support self-management have been developed for chronically ill people $\left[{ }^{10}{ }^{12}\right]$. These programs generally show positive effects on at least some of the outcome variables, but the effects are usually only modest $\left[{ }^{13},{ }^{14}\right]$. For instance, self-management education programs may lead to small, short-term improvements in participants' self-efficacy, self-rated health, cognitive symptom management, and exercise $\left[{ }^{13}\right]$. In addition, still little knowledge exists about effective components and long-term effects of these programs $\left[{ }^{12},{ }^{14}-{ }^{17}\right]$. Tailoring self-management support to patients' self-defined needs might improve the effectiveness of these programs $\left[{ }^{18}\right]$. However, until now most research on selfmanagement has focused on how people perform self-management tasks or how effective a certain self-management support program is; patients' perspective on what self-management entails for themselves and their related needs have been neglected. For example, do people with chronic illness perceive that taking medication as prescribed is one of their tasks, that monitoring their symptoms is something they should do or that they need to change their diet? And what support needs do they have in this respect?

Patients' perceptions of their illness and treatment are a major determining factor of how they cope with their illness $\left[{ }^{19}{ }^{23}\right]$. According to stress-coping theory $\left[{ }^{24}\right]$, people evaluate whether a situation is potentially harmful to their well-being and, if so, what can be done to overcome or prevent the harm (stress appraisal). Assuming that patients' perceptions of self-management tasks provide an indication of the stress they experience, a generally greater need for support could be expected among patients who perceive more self-management tasks for themselves.

Heijmans and colleagues $\left[{ }^{25}\right]$ demonstrated that patients with different chronic conditions perceive many resembling stressors (or adaptive tasks). More specifically, Clark et al. $\left[{ }^{4}\right]$ showed that the essential nature of self-management may be similar across different diseases. However, when considering the existing self-management support programs, it appears that only a few start from a generic perspective on chronic illness. An example of such a program is the Chronic Disease SelfManagement Program, developed at Stanford University $\left[{ }^{26}\right]$. Most self-management support programs, however, focus on one particular disease, for example COPD or diabetes. A limitation of such programs is that they are not always available for patients with less prevalent chronic diseases. Moreover, disease-specific programs do not meet the needs of the many patients who nowadays suffer from multimorbidity $\left[{ }^{27}\right]$. Hence, establishing to what extent self-management tasks and their related support needs are disease specific or of a more generic kind could provide insights to improve self-management support. Therefore, the present study aims to answer the following questions: 
Houtum, L. van, Rijken, M., Heijmans, M., Groenewegen, P. Patient-perceived self-managementh tasks and support needs of people with chronic illness: generic or disease specific? Annals of Behavioral Medicine: 2014

1. Which self-management tasks do people with chronic illness perceive for themselves?

2. Which support needs do people with chronic illness have in this respect?

3. Are there differences in the perceived self-management tasks and support needs according to the type of chronic disease(s) people suffer from?

Before answering these questions, the factor structure and the internal consistency of the self-developed questionnaire to assess patient-perceived self-management tasks and support needs will be examined.

\section{METHOD}

\section{Participants}

For the purpose of this study, data were used from people diagnosed with one (or more) chronic disease(s) who were participating in the National Panel of people with Chronic illness or Disability (NPCD), a nationwide prospective-panel study in the Netherlands $\left[{ }^{28},{ }^{29}\right]$. NPCD was set up in 2005 to provide information about the experiences and consequences of living with chronic illness or disability from the patient's perspective.

NPCD participants with chronic diseases are recruited from (a random sample of) general practices in the Netherlands according to the following criteria: a diagnosis of a somatic chronic disease by a certified medical practitioner, aged $\geq 15$ years, not being institutionalized, being aware of the diagnosis, not being terminally ill [life expectancy $>6$ months according to the general practitioner (GP)], being mentally able to participate, and having sufficient mastery of the Dutch language $\left[{ }^{28},{ }^{29}\right]$. Each year, 500 new panel members are selected via the standardized procedure to replace panel members who withdrew or who had participated for the maximum term of 4 years. Panel members fill in self-reported questionnaires at home twice a year. NPCD is registered with the Dutch Data Protection Authority; all data are collected and handled in accordance with the privacy protection guidelines of the Authority.

\section{Data Collection}

At the start of panel membership, NPCD participants received a questionnaire on their socio-demographic characteristics. In addition, GPs provided (with patients' permission) medical information about panel members. In April 2011, a selfadministered questionnaire about self-management tasks and related support needs was sent by post to 2,542 panel members diagnosed with a chronic disease. To increase the response, a postal reminder was sent to panel members who had not responded yet. The closing date of the questionnaire was late June 2011. A total of 2,064 people completed this questionnaire (81\%).

\section{Operationalization}

\section{Self-Management Tasks and Support Needs}

To assess patients' perceived self-management tasks and support needs, the authors developed the Patient Assessment of Self-management Tasks questionnaire (PAST). In accordance with the description of self-management activities by Bayliss et al. $\left[{ }^{30}\right]$, four dimensions of self-management tasks and support needs were distinguished: (1) medical management, e.g., taking medication correctly or monitoring symptoms; (2) communication with healthcare providers, e.g., visiting 
Houtum, L. van, Rijken, M., Heijmans, M., Groenewegen, P. Patient-perceived self-managementh tasks and support needs of people with chronic illness: generic or disease specific? Annals of Behavioral Medicine: 2014

healthcare providers and understanding information given by healthcare providers; (3) coping with the consequences of the illness, e.g., coping with pain, emotions, and an uncertain future; and (4) making lifestyle changes, e.g., exercising sufficiently or eating a healthy diet. To operationalize the four dimensions, information from the international literature as well as from focus groups held with COPD and diabetes patients was used. In the focus groups, patients discussed the activities/tasks they encounter in their daily life related to their chronic illness. Subsequently, the tasks that were identified through the focus groups were reformulated from COPD- or diabetes-specific descriptions to more generic descriptions. The experiences with self-management of people with COPD and diabetes gave a good idea of the wide range of self-management tasks chronically ill people have to perform in their daily lives, as COPD and diabetes differ both in nature (e.g., symptoms, causes) and in course of illness (e.g., intermittent, progressive deterioration). In addition, patients with diabetes or COPD might have more experiences with self-management as there are advanced disease management programs for these two diseases. The electronic supplementary material (ESM) illustrates the 19 items formulated to assess the four theoretically distinguished dimensions (see ESM 1).

The PAST assesses to what extent patients feel they need to perform different selfmanagement tasks in their daily lives and to what extent they feel a need for support with these tasks, both answered on a four-point scale ranging from 0 (never) to 3 (always). For example, how often do you need to take medication as prescribed and how often do you need support with this? In the introduction of the questionnaire, it was stated that "support could be seen as help from a healthcare provider but also from family or friends". Patients who do not perceive a specific self-management task for themselves did not have to report their need for support with this task. The scales of self-management tasks (four scales) and support needs (four scales) were constructed by summing the scores on the separate items belonging to the scale. Participants had to fill in at least three items per scale to get a scale score.

\section{Illness Characteristics}

The chronic diseases of participants were registered by their GP using the International Classification of Primary Care $\left[{ }^{31}\right]$. Examples of registered diseases are heart failure, Crohn's disease, and multiple sclerosis. Multimorbidity was defined as the presence of more than one chronic somatic disease. In addition, illness duration was derived from the date of diagnosis of the (first) chronic disease as registered in the GP file.

\section{Socio-demographic Characteristics}

The following patient characteristics were included in the study: age, gender, and education level [highest level of completed education, classified as low (primary education, lower secondary and lower vocational education), moderate (intermediate secondary and intermediate vocational education), and high (higher vocational education and university)].

\section{Statistical Analysis}

First, descriptive statistics were computed to get information on the characteristics of the study sample.

Next, the factor structure of the questionnaire was examined. First, we performed an exploratory factor analysis to see how the items cluster together. The results of this 
Houtum, L. van, Rijken, M., Heijmans, M., Groenewegen, P. Patient-perceived self-managementh tasks and support needs of people with chronic illness: generic or disease specific? Annals of Behavioral Medicine: 2014

analysis are shown in the electronic supplementary material (see ESM 2). Second, a series of confirmatory factor analyses were performed to test the theoretically assumed four-factor structure of the PAST (perceived self-management tasks) questionnaire. The fit of the four-factor model was compared with two other models: a null model assuming no relationship between the items of the PAST and an onefactor model assuming that all items make up one single all-encompassing dimension. The extent to which the models fit the data was assessed by chi-square goodness-of-fit statistics. Non-significant chi-squares suggest a satisfactory fit for the tested model $\left[{ }^{32},{ }^{33}\right]$. However, chi-square statistics will nearly always reject the model when large sample sizes are used $\left[{ }^{33}\right]$. Therefore, other measures that are less affected by sample size were computed, namely the non-normed fit index (NNFI), the comparative fit index (CFI), the standardized root mean square residual (SRMR), and the root mean square error of approximation (RMSEA). NNFI and CFI values $\geq 0.95$, SRMR $\leq 0.08$, and RMSEA values $\leq 0.06$ were considered indicative of good model fit $\left[{ }^{34}\right]$. In addition, the modification indices provided by the analysis to establish whether an item assumed to relate to a certain factor better fits one of the other factors were examined. For the factor analysis, only cases that had no missing values were included $(n=1,743)$. Subsequently, the internal consistency of the various self-management tasks and needs scales was computed using Cronbach's alpha.

Descriptive statistics were computed to provide information on what patients perceive as their self-management tasks and what support needs they have in this respect (research questions 1 and 2). In addition, to explore the interrelationships between the self-management tasks and the support needs, Pearson correlation coefficients were computed. To explore whether self-management tasks and support needs relate to the type of chronic illness at stake (research question 3), the effects of disease type on self-management tasks and support needs were estimated by multiple linear regression analyses, controlling for the effects of age, gender, education level, and multimorbidity.

Because intra-class correlations showed hardly any clustering of support needs within general practices (mean 0.01) and the likelihood ratio test did not show that multilevel analyses had an advantage over ordinary regression analyses, single-level regression analyses were conducted. All analyses, except for the confirmatory factor analyses, were performed using Stata 12.0. Confirmatory factor analyses were performed using LISREL 8.8.

\section{RESULTS}

\section{Characteristics of the Study Sample}

Table 1 presents the socio-demographic and illness characteristics of the study sample. The mean age of the respondents was 59 years and more than half were female (56 \%). A third (34\%) had a low education level, $42 \%$ had been moderately educated, and $24 \%$ had a high education level. Cardiovascular disease (23\%), asthma (23\%), diabetes (19\%), and COPD (18\%) were the most common chronic diseases within the sample. Almost half of the respondents (43\%) had been diagnosed with more than one chronic disease. On average, the illness duration was 11 years, but there was a wide variety in illness duration (from recently diagnosed through diagnosed during the first year of life). 
Houtum, L. van, Rijken, M., Heijmans, M., Groenewegen, P. Patient-perceived self-managementh tasks and support needs of people with chronic illness: generic or disease specific? Annals of Behavioral Medicine: 2014

\section{[TABLE 1]}

\section{Factor Structure of the PAST Questionnaire}

Table 2 shows the results of the confirmatory factor analyses. As the modification indices related to the test of the four-factor model fit showed that item 12 is associated with all four factors and not one in particular, the authors decided to test an additional model: a four-factor model without item 12. Item 12 refers to the use of technical aids, such as an inhaler or blood pressure pump. Only a small fraction of the population of people with chronic illness use such technical aids ( $\left.<10 \%\left[{ }^{35}\right]\right)$, which justifies the decision to eliminate item 12.

\section{[TABLE 2]}

Chi-square tests were significant for all four models, but this might be related to the large sample size used in this study. The CFI and SRMR score of respectively 0.95 and 0.05 indicated a good fit of the final model and the NNFI and RSMEA score of respectively 0.94 and 0.07 indicated a reasonable fit of the final model. The authors therefore considered the model fit as confirmation of the four-dimensionality of the PAST (perceived self-management tasks) questionnaire.

Cronbach's alphas were lower for the self-management tasks scales (medical, 0.59; communication, 0.67; coping, 0.82; lifestyle, 0.60) than for the support needs scales (medical, communication, and lifestyle, all 0.79; coping, 0.83), but all indicated an acceptable internal consistency reliability.

\section{Patient-Perceived Self-Management Tasks and Support Needs}

On average, people with chronic illness perceived a moderate amount of selfmanagement tasks for themselves (mean scores between 1.07 and 1.64 on a scale from 0 to 3; Table 3). They faced more tasks (in number and frequency) in medical management and making lifestyle changes than in communication with healthcare providers and coping with the consequences of chronic illness. The results regarding the needs for self-management support were quite different. Overall, participants reported fairly low needs for self-management support, whereas the highest needs for support were found in the domains communication with healthcare providers and coping with the consequences of chronic illness.

\section{[TABLE 3]}

Correlations between the scales for self-management tasks ranged from 0.36 to 0.60 (not in table). The correlations between the scales for support needs were higher, ranging from 0.54 to 0.73 . This indicated that participants who reported a need for support in one particular domain of self-management were more likely to report a need for support in other domains of self-management as well. Furthermore, the correlations between the tasks scales and the support needs scales were low to moderate (range 0.11-0.51), indicating that perceiving a particular self-management task did not necessarily imply a related support need.

\section{Perceived Self-Management Tasks and Support Needs According to Disease Type}

Table 4 shows that the type of chronic disease participants were suffering from related to some extent to the self-management tasks they perceived as part of their daily management. However, the effects of disease types varied for the four domains of self-management. For instance, people suffering from arthritis perceived more 
Houtum, L. van, Rijken, M., Heijmans, M., Groenewegen, P. Patient-perceived self-managementh tasks and support needs of people with chronic illness: generic or disease specific? Annals of Behavioral Medicine: 2014

self-management tasks for themselves (compared to people with other types of chronic diseases) regarding communication with healthcare providers and coping with the consequences of their illness, but not regarding medical management tasks and making lifestyle changes. Two disease types had a substantial effect on the extent to which people perceived tasks as part of their daily management. Having diabetes had a strong effect on perceiving more tasks in the domains of medical management, communication, and lifestyle, and having a neurological disease had a strong effect on communication and coping.

\section{[TABLE 4]}

With regard to the needs for self-management support, disease types less often had significant effects. A diagnosis of a neurological disease, musculoskeletal disorder, diabetes, COPD, or cancer (reference-no such diagnosis) had significant positive effects on the need for self-management (in one or more domains), but in general these effects were small (and smaller than the effects of disease types on the perceived self-management tasks).

Furthermore, being older, female, or low educated related to a perception of more tasks as part of the daily management of a chronic illness and to higher needs for self-management support. These effects also differed for the four domains of selfmanagement. Having more than one chronic illness related to the amount of selfmanagement tasks people perceive for themselves regarding medical management.

\section{DISCUSSION}

This study shows that people with chronic illness perceive a moderate amount of self-management tasks for themselves. Especially in the domains of medical management and making lifestyle changes, they perceive more self-management tasks. People with chronic illness who face (more) tasks in one domain of selfmanagement do not necessarily face (more) tasks in other domains as well. Moreover, people who perceive more self-management tasks do not automatically indicate a higher need for support. Overall, people with chronic illness indicated a fairly low need for self-management support, but people who report a need for support in one domain of self-management probably also need support in other domains of self-management.

The generally low need for self-management support that people with chronic illness reported in this study may be somewhat surprising. It may be explained by the fact that this study assessed the unmet needs for support of the participants, thus not their needs for self-management support that had already been met by the support they received from informal carers and professional care providers. The reason for this is that the actual amount of support people already receive cannot be reliably estimated by self-report, as people who receive similar levels of support may experience the provided support differently. In addition, the authors believe that information on the still existing (unmet) needs is most relevant to improve self-management support for people with chronic illness. Furthermore, the fact that people with chronic illness report a low need for support does not necessarily mean that they will not benefit from support. People with chronic illness may not always explicitly state their needs for support.

People with chronic illness report the highest levels of perceived self-management tasks in the domains of medical management and making lifestyle changes, whereas 
Houtum, L. van, Rijken, M., Heijmans, M., Groenewegen, P. Patient-perceived self-managementh tasks and support needs of people with chronic illness: generic or disease specific? Annals of Behavioral Medicine: 2014

they report the lowest needs for support with respect to these domains. Findings of Elissen and colleagues $\left[{ }^{36}\right]$ showed that self-management support provided by healthcare providers tend to focus mainly on medical and behavioral management of an illness and less on helping patients deal with the emotional consequences of being chronically ill. Because of the emphasis healthcare providers put on the medical and behavioral aspects, patients may perceive the medical management of their illness and making lifestyle changes more often as their self-management tasks than coping with the consequences of chronic illness for their daily life. The focus on medical and behavioral aspects of self-management in healthcare may also explain why people report a lower need for support in these domains: they already receive sufficient support from healthcare providers in this respect. Moreover, selfmanagement tasks in the medical and lifestyle domains may be more concrete and straightforward than tasks concerning complex processes such as adaptation to a life with chronic illness, resulting in higher support needs regarding coping tasks. Previous research indicated that there are commonalities in the nature of selfmanagement tasks across different types of diseases $\left[{ }^{4},{ }^{25}\right]$. The current study found that self-management tasks are partly generic and partly disease specific. Most types of chronic disease had only a small effect on the number and frequencies of perceived self-management tasks. However, having diabetes or a neurological disease did have a strong effect on the extent to which people perceive tasks as part of their daily management. In many European countries, there are advanced disease management programs for diabetes and not (yet) or only recently for other chronic diseases $\left[{ }^{27}\right]$. It could be that this has led diabetes patients to be more aware of their own role in the management of diabetes, resulting in these patients perceiving more tasks as part of their daily self-management. Neurological diseases, such as Parkinson's disease and multiple sclerosis, are in general progressive diseases that strongly affect people's cognitive and physical functioning. This might explain why having a neurological disease had especially a strong effect on the perceived selfmanagement tasks concerning communication and coping with the chronic disease. Moreover, this study does show that there are similarities in the self-management support needs for the different diseases. The effects of the different types of diseases on self-management support needs were small and explained only a small proportion of the variation in support needs of chronically ill people. This is an important finding as the type of chronic disease is for many self-management support programs the most important inclusion criterion. This study indicates that developing generic self-management support programs with disease-specific modules that can be added could help optimize the outcomes of these programs. These programs would also better meet the needs of the many patients that suffer from more than one chronic disease. This study only focused on having one or more chronic diseases. The effect of combinations of specific types of chronic diseases on self-management tasks and support needs was not taken into account. It would be interesting to examine the effect of multimorbidity on self-management support needs more thoroughly. In addition, further research should focus on the self-management support needs of different target groups to establish how self-management programs can be tailored to the individual needs of patients.

\section{Strengths and Limitations of the Study}

This is, to the best of our knowledge, one of the first studies that evaluates selfmanagement tasks and support needs from the perspective of people with chronic 
Houtum, L. van, Rijken, M., Heijmans, M., Groenewegen, P. Patient-perceived self-managementh tasks and support needs of people with chronic illness: generic or disease specific? Annals of Behavioral Medicine: 2014

illness themselves and the only study that uses quantitative data from a large study population. The use of data from a nationwide representative sample of (medically diagnosed) chronically ill people provides unique insights into the perceptions of people with chronic illness. For this study, a self-developed questionnaire was used and therefore some aspects of the psychometric quality of the questionnaire were tested: its factor structure and (internal consistency) reliability. Our results indicate that the PAST questionnaire supports the theoretically presumed multidimensionality of the concept of self-management. The four-factor model fits the data reasonably well. Furthermore, the internal consistency of the tasks and support scales are acceptable. The somewhat low alpha for the medical management scale might be explained by the diversity of the tasks involved. Some people will have to perform self-care tasks, such as putting on elastic stockings and some people might need to monitor their blood pressure, but the fact that someone needs to perform one type of medical task does not directly imply the need to perform the other tasks as well. Nevertheless, all these tasks involve medical management. The same principle applies to the lifestyle scale. For some patients, making lifestyle changes will mean losing weight and for others stopping smoking. In addition, people tend to compensate unhealthy behavior with healthy behavior $\left[{ }^{37}\right]$. For instance, "If I exercise sufficiently, I am allowed to eat fast food". This might explain the slightly low alpha for the lifestyle scale. However, test-retest reliability and construct validity of the questionnaire need to be further examined. In addition, the factor structure of the questionnaire should also be tested in different data samples. If the PAST questionnaire proves sufficiently reliable and valid, it could be useful for tailoring self-management programs to the individual needs of chronically ill people. Healthcare providers could use the questionnaire to assess patients' unmet support needs.

\section{CONCLUSION}

Although people with chronic illness perceive a moderate amount of selfmanagement tasks for themselves, they do not indicate an explicit need for selfmanagement support. The need for self-management support of people with chronic illness is not strongly related to the extent to which they perceive more or less selfmanagement tasks for themselves, nor can it be satisfactorily explained by the specific type of chronic disease they are diagnosed with. This indicates that though the self-management tasks patients see for themselves may be partly disease specific, self-management support does not necessarily need to be disease specific. Support programs could use a more generic approach and should not only focus on medical management of the illness and making lifestyle changes but also pay attention to coping with the consequences of living with a chronic illness.

\section{Acknowledgments}

The authors thank all people who responded to the questionnaires.

\section{Support}

This study formed part of the research program "National Panel of people with Chronic illness or Disability”, which is financed by the Netherlands Ministry of Public Health, Welfare and Sports and the Netherlands Ministry of Social Affairs and Employment. This study is part of a $\mathrm{PhD}$ project that is financed by the Netherlands Ministry of Education, Culture and Science. 
Houtum, L. van, Rijken, M., Heijmans, M., Groenewegen, P. Patient-perceived self-managementh tasks and support needs of people with chronic illness: generic or disease specific? Annals of Behavioral Medicine: 2014

Authors' Statement of Conflict of Interest and Adherence to Ethical Standards Lieke van Houtum, Monique Heijmans, Mieke Rijken, and Peter Groenewegen declare that they have no conflict of interest. All procedures, including the informed consent process, were conducted in accordance with the Helsinki Declaration of 1975, as revised in 2000. According to the Dutch Medical Research Involving Human Subjects Act, this study does not require ethics approval.

\section{ELECTRONIC SUPPLEMENTARY MATERIAL}

Below is the link to the electronic supplementary material.

\section{REFERENCES}

1. Yach D, Hawkes C, Gould C, Hofman K. The global burden of chronic disease: overcoming impediments to prevention and control. JAMA. 2004; 291: 2616-2622.

2. WHO. Global Status Report on Global Non-communicable Disease 2010. Geneva: WHO Document Production Services; 2011.

3. Barlow J, Wright C, Sheasby J, Turner A, Hainsworth J. Self-management approaches for people with chronic conditions: a review. Patient Educ Couns. 2002; 48: 177-187.

4. Clark N, Becker M, Janz N, Lorig K, Rakowski W, Anderson L. Self-management of chronic disease by older adults. J Aging Health. 1991; 3: 3-27.

5. Glasgow R, David C, Funnell M, Beck A. Implementing practical interventions to support chronic illness self-management. Joint Comm J Qual Safety. 2003; 29: 563-574.

6. Lorig K, Holman H. Self-management education: history, definition, outcomes and mechanisms. Ann Behav Med. 2003; 26: 1-7.

7. Redman $B$. The ethics of self-management preparation for chronic illness. Nursing Ethics. 2005; 12: 360-369.

8. Newman S, Steed L, Mulligan K. Self-management interventions for chronic illness. Lancet. 2004; 364: 1523-1537.

9. Jerant AF, Von Friederichs-Fitzwater MM, Moore M. Patients' perceived barriers to active self-management of chronic conditions. Patient Educ Couns. 2005; 57: 300-307.

10. Jordan J, Osborn R. Chronic disease self-management education programs: challenges ahead. Med J Aust. 2007; 186: 84-87.

11. Rijken M, Jones M, Heijmans M, Dixon A. Supporting self-management. In: Nolte E, McKee M, eds. Caring for People with Chronic Conditions. A Health System Perspective. Berkshire, UK: Open University Press; 2008: 116-142.

12. Warsi A, Wang P, LaValley M, Avorn J, Solomon D. Self-management education programs in chronic disease: a systematic review and methodological critique of the literature. Arch Intern Med. 2004; 164: 1641-1649.

13. Foster G, Taylor SJ, Eldridge SE, Ramsay J, Griffiths CJ. Self-management education programmes by lay leaders for people with chronic conditions. Cochrane Database Syst Rev. 2007;CD005108.

14. Deakin TA, McShane CE, Cade JE, Williams R. Group based training for selfmanagement strategies in people with type 2 diabetes mellitus. Cochrane Database Syst Rev. 2005;(2):CD003417.

15. Gibson PG, Powell H, Wilson A, et al. Self-management education and regular practitioner review for adults with asthma. Cochrane Database Syst Rev. 2002;(2):CD001117.

16. Gardetto N. Self-management in hearth failure: where have we been and where should we go? J Multidiscip Healthc. 2011; 4: 39-51.

17. Ursum J, Rijken M, Heijmans M, Cardol M, Schellevis F. Zorg voor chronisch zieken: Organisatie van zorg, zelfmanagement, zelfredzaamheid en participatie. Utrecht: NIVEL; 2011.

18. Trappenburg J, Jonkman N, Jaarsma T, et al. Self-management: one size does not fit all. Patient Educ Couns. 2013; 92: 134-137. 
Houtum, L. van, Rijken, M., Heijmans, M., Groenewegen, P. Patient-perceived self-managementh tasks and support needs of people with chronic illness: generic or disease specific? Annals of Behavioral Medicine: 2014

19. DiMatteo M, Haskard K, Williams S. Health beliefs, disease severity, and patient adherence. A meta-analysis. Med Care. 2007; 45: 521-528.

20. Jansen D, Grootendorst D, Rijken M, et al. Predialysis patients' perceives autonomy, self-esteem and labour participation: associations with illness perceptions and treatment perceptions. A cross-sectional study. BMC Nephrol. 2010;11.

21. Kaptein A, Hughes B, Scharloo M, et al. Illness perceptions about asthma are determinants of outcome. J Asthma. 2008; 45: 459-464.

22. Leventhal H, Diefenbach M. Illness cognition: using common sense to understand treatment adherence and affect cognition interactions. Cogn Ther Res. 1992; 16: 143-163.

23. Scharloo M, Kaptein A, Weinman J, et al. Illness perceptions, coping and functioning in patients with rheumatoid arthritis, chronic obstructive pulmonary disease and psoriasis. J Psychosom Res. 1998; 44: 573-585.

24. Lazarus R, Folkman S. Stress, Appraisal, and Coping. New York: Pergamon; 1984.

25. Heijmans M, Rijken M, Foets M, De Ridder D, Schreurs K, Bensing J. The stress of being chronically ill: from disease-specific to task-specific aspects. J Behav Med. 2004; 27: 255-271.

26. Lorig KR, Ritter P, Stewart AL, et al. Chronic disease self-management program: 2-year health status and health care utilization outcomes. Med Care. 2001; 39: 1217-1223.

27. Rijken M, Bekkema N, Boeckxstaen P, Schellevis FG, Maeseneer JM de, Groenewegen PP. Chronic Disease Management Programmes: an adequate response to patients' needs? Health Expectations. 2012.

28. Rijken M, Bensing J. Het nationaal Patiëntenpanel Chronisch Zieken. Een onderzoeksinfrastructuur voor patiëntengericht onderzoek. Utrecht: NIVEL; 2000.

29. Rijken M, Groenewegen P. Money does not bring well-being, but it does help! The relationship between financial resources and life satisfaction of chronically ill mediated by social deprivation and loneliness. J Commun Appl Soc Psychol. 2008; 18: 39-53.

30. Bayliss E, Steiner J, Fernald D, Crane L, Main D. Descriptions of barriers to self-care by persons with comorbid chronic diseases. Ann Fam Med. 2003; 1: 15-21.

31. Lamberts H, Wood M. ICPD. International Classification of Primary Care. Oxford: Oxford University Press; 1987.

32. Hooper D, Coughlan J, Mullen M. Structural equation modelling: guidelines for determining model fit. Electron J Bus Res Methods. 2008; 6: 53-60.

33. Jörskog K, Sörbom D. LISREL 8: Structural Equation Modelling with the SIMPLIS Command Language. Chicago: Scientific Software International Inc.; 1993.

34. Hu L, Bentler P. Cutoff criteria for fit indexes in covariance structure analysis: conventional criteria versus new alternatives. Struct Equ Model. 1999; 6: 1-55.

35. Dekker J, Rijken M, van Poppels M, de Bruin A. The possession of technical aids among persons with somatic chronic disease. Disabil Rehabil. 2003; 26: 393-398.

36. Elissen A, Nolte E, Knai C, et al. Is Europe putting theory into practice? A qualitative study of level of self-management support in chronic care approaches. BMC Health Serv Res. 2013; 13: 117-126.

37. Rabiau M, Knauper B, Miquelon $\mathrm{P}$. The external quest for optimal balance between maximizing pleasure and minimizing harm: the compensatory health beliefs model. $\mathrm{Br} \mathrm{J}$ Health Psychol. 2006; 11: 139-153. 
Houtum, L. van, Rijken, M., Heijmans, M., Groenewegen, P. Patient-perceived self-management tasks and support needs of people with chronic illness: generic or disease specific? Annals of Behavioral Medicine: 2014

TABLES

Table 1 : Respondents' socio-demographic and illness characteristics $(\mathrm{n}=2,064)$

\begin{tabular}{|c|c|c|c|c|c|}
\hline & $\mathbf{n}$ & Percentage & Mean & Range & SD \\
\hline \multicolumn{6}{|l|}{ Patient characteristics } \\
\hline Age & 2,064 & & 59.3 & $15-93$ & 16.0 \\
\hline Female & 1,156 & $56 \%$ & & & \\
\hline \multicolumn{6}{|l|}{ Education level } \\
\hline Lower & 690 & $34 \%$ & & & \\
\hline Intermediate & 849 & $42 \%$ & & & \\
\hline Higher & 482 & $24 \%$ & & & \\
\hline \multicolumn{6}{|l|}{ Illness characteristics } \\
\hline \multicolumn{6}{|l|}{ Diagnosis disease } \\
\hline Cardiovascular disease & 475 & $23 \%$ & & & \\
\hline Asthma & 478 & $23 \%$ & & & \\
\hline Chronic obstructive pulmonary disease & 371 & $18 \%$ & & & \\
\hline Other chronic respiratory disease & 140 & $7 \%$ & & & \\
\hline Arthritis & 240 & $12 \%$ & & & \\
\hline Other chronic musculoskeletal disorder & 151 & $7 \%$ & & & \\
\hline Cancer & 141 & $7 \%$ & & & \\
\hline Diabetes mellitus & 384 & $19 \%$ & & & \\
\hline Thyroid dysfunction & 147 & $7 \%$ & & & \\
\hline Migraine & 83 & $4 \%$ & & & \\
\hline Neurological disease & 106 & $5 \%$ & & & \\
\hline Chronic digestive disease & 140 & $6 \%$ & & & \\
\hline Chronic skin disease & 163 & $8 \%$ & & & \\
\hline Other chronic disease & 232 & $11 \%$ & & & \\
\hline Multimorbidity present & 894 & $43 \%$ & & & \\
\hline Illness duration (years post-diagnosis) & & & 11.3 & $0-87$ & 9.0 \\
\hline Less than 5 years & 409 & $21 \%$ & & & \\
\hline 5 to 10 years & 714 & $35 \%$ & & & \\
\hline 10 years or longer & 916 & $44 \%$ & & & \\
\hline
\end{tabular}


Houtum, L. van, Rijken, M., Heijmans, M., Groenewegen, P. Patient-perceived self-management tasks and support needs of people with chronic illness: generic or disease specific? Annals of Behavioral Medicine: 2014

Table 2 : Measures of fit of four different models of the PAST questionnaire $(\mathrm{n}=1,743)$

\begin{tabular}{|l|c|c|c|c|c|c|}
\hline Sample and model & $\chi^{2}$ & df & NNFI & CFI & SRMR & RMSEA \\
\hline Null model & $24,281.32^{*}$ & 171 & & & & \\
\hline 1-factor model & $2,549.99^{*}$ & 152 & 0.90 & 0.91 & 0.07 & $0.10^{*}$ \\
\hline 4-factor model & $1,621.31^{*}$ & 146 & 0.93 & 0.91 & 0.06 & $0.08^{*}$ \\
\hline 4-factor model without item 12 & $1,235.35^{*}$ & 129 & 0.94 & 0.95 & 0.05 & $0.07 *$ \\
\hline
\end{tabular}

NNFI non-normed fit index, CFI comparative fit index, SRMR standardized root mean square residual, RMSEA root mean square error of approximation

*Significant at $\mathrm{p}<0.01$

Table 3: Patient-perceived self-management tasks and support needs (scale 0-3)

\begin{tabular}{|l|c|c|c|c|c|c|}
\hline & \multicolumn{2}{|c|}{$\begin{array}{c}\text { Self-management } \\
\text { tasks }\end{array}$} & \multicolumn{2}{|c|}{$\begin{array}{c}\text { Self-management support } \\
\text { needs }\end{array}$} \\
\cline { 2 - 5 } & $\mathbf{n}$ & Mean & SD & n & Mean & SD \\
\hline Medical management & 1,998 & 1.64 & 0.69 & 1,202 & 0.41 & 0.51 \\
\hline $\begin{array}{l}\text { Communication with healthcare } \\
\text { providers }\end{array}$ & 1,983 & 1.07 & 0.63 & 1,110 & 0.64 & 0.59 \\
\hline Coping with the consequences & 1,990 & 1.13 & 0.74 & 1,338 & 0.64 & 0.58 \\
\hline Making lifestyle changes & 1,978 & 1.57 & 0.74 & 1,230 & 0.48 & 0.60 \\
\hline
\end{tabular}

Table 4: Multiple linear regression analyses testing the effect of type of illness on perceived self-management tasks and support needs of patients with chronic illness (regression coefficient and standard error)

\begin{tabular}{|c|c|c|c|c|c|c|c|c|}
\hline & \multicolumn{4}{|c|}{ Self-management tasks } & \multicolumn{4}{|c|}{ Self-management support needs } \\
\hline & \begin{tabular}{|c|}
$\begin{array}{c}\text { Medic } \\
\text { al }\end{array}$ \\
\end{tabular} & \begin{tabular}{|c|} 
Communi \\
cation
\end{tabular} & $\begin{array}{c}\text { Copin } \\
\mathrm{g}\end{array}$ & $\begin{array}{c}\text { Lifesty } \\
\text { le }\end{array}$ & $\begin{array}{c}\text { Medic } \\
\text { al }\end{array}$ & $\begin{array}{c}\text { Communi } \\
\text { cation }\end{array}$ & $\begin{array}{c}\text { Copin } \\
\mathrm{g}\end{array}$ & $\begin{array}{c}\text { Lifesty } \\
\text { le }\end{array}$ \\
\hline & $\begin{array}{c}(\mathrm{n}=1, \\
960)\end{array}$ & $(n=1,945)$ & $\begin{array}{c}(\mathrm{n}=1, \\
953)\end{array}$ & $\begin{array}{c}(n=1, \\
941)\end{array}$ & $\begin{array}{c}(\mathrm{n}=1, \\
176)\end{array}$ & 086) & $\begin{array}{c}(\mathrm{n}=1, \\
313)\end{array}$ & $\begin{array}{c}(\mathrm{n}=1 \\
208)\end{array}$ \\
\hline Cons & $\begin{array}{l}0.82 \\
(0.099)\end{array}$ & \begin{tabular}{|l}
0.43 \\
$(0.091)$
\end{tabular} & $\begin{array}{l}0.30 \\
(0.107)\end{array}$ & $\begin{array}{l}1.01 \\
(0.110)\end{array}$ & $\begin{array}{l}0.21 \\
(0.098)\end{array}$ & $\begin{array}{l}0.11 \\
(0.114)\end{array}$ & $\begin{array}{l}0.29 \\
(0.107)\end{array}$ & $\begin{array}{l}0.50 \\
(0.119)\end{array}$ \\
\hline \multicolumn{9}{|c|}{ Type of illness $^{a}$} \\
\hline $\begin{array}{l}\text { Cardiovas } \\
\text { cular }\end{array}$ & $\begin{array}{l}0.11 \\
(0.049) \\
*\end{array}$ & $\begin{array}{l}0.10 \\
(0.045)^{*}\end{array}$ & $\begin{array}{l}0.12 \\
(0.053) \\
* *\end{array}$ & $\begin{array}{l}0.09 \\
(0.054)\end{array}$ & $\begin{array}{l}0.07 \\
(0.046)\end{array}$ & $\begin{array}{l}0.09 \\
(0.054)\end{array}$ & $\begin{array}{l}0.04 \\
(0.050)\end{array}$ & $\begin{array}{l}0.06 \\
(0.056)\end{array}$ \\
\hline Asthma & $\begin{array}{l}0.03 \\
(0.046)\end{array}$ & $\begin{array}{l}-0.01 \\
(0.042)\end{array}$ & $\begin{array}{l}0.00 \\
(0.050)\end{array}$ & $\begin{array}{l}0.03 \\
(0.051)\end{array}$ & $\begin{array}{l}0.01 \\
(0.044)\end{array}$ & $\begin{array}{l}0.01 \\
(0.052)\end{array}$ & $\begin{array}{l}-0.05 \\
(0.048)\end{array}$ & $\begin{array}{l}-0.06 \\
(0.054)\end{array}$ \\
\hline COPD & $\begin{array}{l}0.06 \\
(0.050)\end{array}$ & $\begin{array}{l}0.13 \\
(0.045)^{* *}\end{array}$ & $\begin{array}{l}0.18 \\
(0.054) \\
* *\end{array}$ & $\begin{array}{l}0.11 \\
(0.055)\end{array}$ & $\begin{array}{l}0.01 \\
(0.047)\end{array}$ & $\begin{array}{l}0.13 \\
(0.057)^{*}\end{array}$ & $\begin{array}{l}0.08 \\
(0.052)\end{array}$ & $\begin{array}{l}0.11 \\
(0.058)\end{array}$ \\
\hline
\end{tabular}


Houtum, L. van, Rijken, M., Heijmans, M., Groenewegen, P. Patient-perceived self-management tasks and support needs of people with chronic illness: generic or disease specific? Annals of Behavioral Medicine: 2014

\begin{tabular}{|c|c|c|c|c|c|c|c|c|}
\hline & \multicolumn{4}{|c|}{ Self-management tasks } & \multicolumn{4}{|c|}{ Self-management support needs } \\
\hline & \begin{tabular}{|c|}
$\begin{array}{c}\text { Medic } \\
\text { al }\end{array}$ \\
\end{tabular} & \begin{tabular}{|c} 
Communi \\
cation
\end{tabular} & $\begin{array}{c}\text { Copin } \\
\mathbf{g}\end{array}$ & $\begin{array}{c}\text { Lifesty } \\
\text { le }\end{array}$ & $\begin{array}{c}\text { Medic } \\
\text { al }\end{array}$ & \begin{tabular}{|c|}
$\begin{array}{c}\text { Communi } \\
\text { cation }\end{array}$ \\
\end{tabular} & $\begin{array}{c}\text { Copin } \\
\mathbf{g}\end{array}$ & $\begin{array}{c}\text { Lifesty } \\
\text { le }\end{array}$ \\
\hline & \begin{tabular}{|l}
$(\mathrm{n}=1$, \\
$960)$
\end{tabular} & $(n=1,945)$ & $\begin{array}{c}(n=1 \\
953)\end{array}$ & $\begin{array}{c}(n=1 \\
941)\end{array}$ & $\begin{array}{c}(\mathrm{n}=1, \\
176)\end{array}$ & $(\mathrm{n}=\mathbf{1 , 0 8 6})$ & $\begin{array}{l}(n=1, \\
313)\end{array}$ & $\begin{array}{c}(n=1 \\
208)\end{array}$ \\
\hline $\begin{array}{l}\text { Rest } \\
\text { dis }\end{array}$ & $\begin{array}{l}-0.02 \\
(0.067)\end{array}$ & $\begin{array}{l}-0 . \\
(0.0\end{array}$ & $\begin{array}{l}5 \\
072)\end{array}$ & $\begin{array}{l}-0.10 \\
(0.074)\end{array}$ & $\begin{array}{l}0.05 \\
(0.067)\end{array}$ & 79) & $74)$ & $\begin{array}{l}-0.06 \\
(0.079)\end{array}$ \\
\hline Arth & $\begin{array}{l}0.08 \\
(0.054)\end{array}$ & $\begin{array}{l}0.14 \\
(0.050) * *\end{array}$ & $\begin{array}{l}0.21 \\
(0.059) \\
* *\end{array}$ & $\begin{array}{l}-0.05 \\
(0.060)\end{array}$ & $\begin{array}{l}0.10 \\
(0.051)\end{array}$ & $\begin{array}{l}0.09 \\
(0.061)\end{array}$ & $\begin{array}{l}9 \\
056)\end{array}$ & $\begin{array}{l}-0.01 \\
(0.067)\end{array}$ \\
\hline $\begin{array}{l}\text { Musculos } \\
\text { keletal } \\
\text { disorder }\end{array}$ & $\begin{array}{l}-0.05 \\
(0.063)\end{array}$ & $\begin{array}{l}0.12 \\
(0.058) *\end{array}$ & $\begin{array}{l}0.19 \\
(0.063) \\
* *\end{array}$ & $\begin{array}{l}0.08 \\
(0.070)\end{array}$ & $\begin{array}{l}0.08 \\
(0.061)\end{array}$ & $\begin{array}{l}0.18 \\
(0.068) * *\end{array}$ & $\begin{array}{l}0.13 \\
(0.064) \\
*\end{array}$ & $\begin{array}{l}0.21 \\
(0.075) \\
* *\end{array}$ \\
\hline $\mathrm{C}$ & $\begin{array}{l}0.03 \\
(0.065)\end{array}$ & $\begin{array}{l}0.19 \\
(0.059) * *\end{array}$ & $\begin{array}{l}0.23 \\
(0.070) \\
* *\end{array}$ & $\begin{array}{l}0.12 \\
(0.072)\end{array}$ & $\begin{array}{l}0.12 \\
(0.063)\end{array}$ & $\begin{array}{l}0.18 \\
(0.072)^{*}\end{array}$ & $67)$ & $\begin{array}{l}0.04 \\
(0.077)\end{array}$ \\
\hline Diab & $\begin{array}{l}0.38 \\
(0.048) \\
* *\end{array}$ & $\begin{array}{l}0.32 \\
(0.044) * *\end{array}$ & $\begin{array}{l}0.06 \\
(0.052)\end{array}$ & $\begin{array}{l}0.34 \\
(0.053) \\
* *\end{array}$ & $\begin{array}{l}0.09 \\
(0.044) \\
*\end{array}$ & $\begin{array}{l}-0.00 \\
(0.052)\end{array}$ & $\begin{array}{l}-0.01 \\
(0.051)\end{array}$ & $\begin{array}{l}0.12 \\
(0.054) \\
*\end{array}$ \\
\hline $\begin{array}{l}\text { Thyroid } \\
\text { dysfunctio } \\
n\end{array}$ & $\begin{array}{l}0.03 \\
(0.064)\end{array}$ & $\begin{array}{l}0.04 \\
(0.058)\end{array}$ & 69) & $\begin{array}{l}0.06 \\
(0.071)\end{array}$ & $\begin{array}{l}0.06 \\
(0.063)\end{array}$ & $\begin{array}{l}-0 \\
(0 .\end{array}$ & $\begin{array}{l}.04 \\
.066)\end{array}$ & $\begin{array}{l}0.00 \\
(0.075)\end{array}$ \\
\hline Mig & $\begin{array}{l}-0.11 \\
(0.080)\end{array}$ & & & $\begin{array}{l}-0.07 \\
(0.089)\end{array}$ & $\begin{array}{l}-0.03 \\
(0.075)\end{array}$ & & $\begin{array}{l}0.02 \\
(0.080)\end{array}$ & $\begin{array}{l}-0.04 \\
(0.092)\end{array}$ \\
\hline $\begin{array}{l}\text { Neurologi } \\
\text { cal disease }\end{array}$ & $\begin{array}{l}0.12 \\
(0.072)\end{array}$ & $\begin{array}{l}0.29 \\
(0.066) * *\end{array}$ & $\begin{array}{l}0.54 \\
(0.078) \\
* *\end{array}$ & $\begin{array}{l}-0.07 \\
(0.080)\end{array}$ & $\begin{array}{l}0.24 \\
(0.071) \\
* *\end{array}$ & $\begin{array}{l}0.24 \\
(0.075) * *\end{array}$ & $\begin{array}{l}0.23 \\
(0.072) \\
* *\end{array}$ & $\begin{array}{l}0.12 \\
(0.089)\end{array}$ \\
\hline $\begin{array}{l}\text { Digestive } \\
\text { disorder }\end{array}$ & $\begin{array}{l}0.02 \\
(0.065)\end{array}$ & $\begin{array}{l}0.12 \\
(0.059)\end{array}$ & $\begin{array}{l}0.21 \\
(0.070) \\
* *\end{array}$ & $\begin{array}{l}-0.04 \\
(0.072)\end{array}$ & $\begin{array}{l}0.11 \\
(0.062)\end{array}$ & $\begin{array}{l}0.04 \\
(0.0\end{array}$ & $\begin{array}{l}0.08 \\
(0.065)\end{array}$ & $\begin{array}{l}0.06 \\
(0.071)\end{array}$ \\
\hline $\begin{array}{r}\text { Skin } \\
\text { disease }\end{array}$ & $\begin{array}{l}-0.11 \\
(0.062)\end{array}$ & $\begin{array}{l}0.03 \\
(0.057)\end{array}$ & $\begin{array}{l}-0.02 \\
(0.067)\end{array}$ & $\begin{array}{l}0.00 \\
(0.068)\end{array}$ & $\begin{array}{l}-0.06 \\
(0.060)\end{array}$ & $\begin{array}{l}0.02 \\
(0.070)\end{array}$ & $65)$ & $\begin{array}{l}0.02 \\
(0.063)\end{array}$ \\
\hline $\begin{array}{l}\text { Other } \\
\text { disease }\end{array}$ & $\begin{array}{l}-0.02 \\
(0.055)\end{array}$ & $\begin{array}{l}0.08 \\
(0.050)\end{array}$ & $\begin{array}{l}0.03 \\
(0.059)\end{array}$ & $\begin{array}{l}0.03 \\
(0.061)\end{array}$ & $\begin{array}{l}0.08 \\
(0.052)\end{array}$ & $\begin{array}{l}0.11 \\
(0.062)\end{array}$ & $\begin{array}{l}0.05 \\
(0.058)\end{array}$ & $\begin{array}{l}0.02 \\
(0.056)\end{array}$ \\
\hline Age & $\begin{array}{l}0.01 \\
(0.001) \\
* *\end{array}$ & $\begin{array}{l}0.01 \\
(0.001)^{* *}\end{array}$ & $\begin{array}{l}0.01 \\
(0.001) \\
* *\end{array}$ & $\begin{array}{l}0.01 \\
(0.001) \\
* *\end{array}$ & $\begin{array}{l}0.00 \\
(0.001) \\
* *\end{array}$ & $\begin{array}{l}0.01 \\
(0.001)^{* *}\end{array}$ & $\begin{array}{l}0.00 \\
(0.001) \\
*\end{array}$ & $\begin{array}{l}-0.00 \\
(0.001)\end{array}$ \\
\hline Gender ${ }^{b}$ & $\begin{array}{l}0.11 \\
(0.032) \\
* *\end{array}$ & $\begin{array}{l}0.11 \\
(0.029)^{* *}\end{array}$ & $\begin{array}{l}0.19 \\
(0.034) \\
* *\end{array}$ & $\begin{array}{l}0.08 \\
(0.035) \\
*\end{array}$ & $\begin{array}{l}-0.02 \\
(0.031)\end{array}$ & $\begin{array}{l}0.10 \\
(0.037)^{* *}\end{array}$ & $\begin{array}{l}0.10 \\
(0.034) \\
* *\end{array}$ & $\begin{array}{l}0.03 \\
(0.037)\end{array}$ \\
\hline
\end{tabular}




\begin{tabular}{|c|c|c|c|c|c|c|c|c|}
\hline & \multicolumn{4}{|c|}{ Self-management tasks } & \multicolumn{4}{|c|}{ Self-management support needs } \\
\hline & \begin{tabular}{|c} 
Medic \\
al
\end{tabular} & $\begin{array}{c}\text { Communi } \\
\text { cation }\end{array}$ & $\begin{array}{c}\text { Copin } \\
\mathbf{g}\end{array}$ & $\begin{array}{c}\text { Lifesty } \\
\text { le }\end{array}$ & $\begin{array}{c}\text { Medic } \\
\text { al }\end{array}$ & $\begin{array}{c}\text { Communi } \\
\text { cation }\end{array}$ & \begin{tabular}{|c|} 
Copin \\
$\mathrm{g}$
\end{tabular} & $\begin{array}{c}\text { Lifesty } \\
\text { le }\end{array}$ \\
\hline & \begin{tabular}{|c}
$(n=1$, \\
$960)$
\end{tabular} & $(\mathrm{n}=\mathbf{1 , 9 4 5})$ & $\begin{array}{l}(\mathrm{n}=1, \\
953)\end{array}$ & $\begin{array}{c}(\mathrm{n}=1, \\
941)\end{array}$ & $\begin{array}{c}(\mathrm{n}=1, \\
176)\end{array}$ & $(\mathrm{n}=\mathbf{1 , 0 8 6})$ & $\begin{array}{c}(\mathrm{n}=1, \\
313)\end{array}$ & $\begin{array}{c}(\mathrm{n}=1, \\
208)\end{array}$ \\
\hline \multicolumn{9}{|c|}{ Educational level $^{\mathrm{C}}$} \\
\hline Middle & $\begin{array}{l}-0.00 \\
(0.035)\end{array}$ & $\begin{array}{l}-0.08 \\
(0.032)^{*}\end{array}$ & $\begin{array}{l}-0.03 \\
(0.038)\end{array}$ & $\begin{array}{l}-0.01 \\
(0.039)\end{array}$ & $\begin{array}{l}-0.09 \\
(0.035) \\
*\end{array}$ & $\begin{array}{l}-0.16 \\
(0.041)^{* *}\end{array}$ & $\begin{array}{l}-0.06 \\
(0.038)\end{array}$ & $\begin{array}{l}-0.08 \\
(0.041)\end{array}$ \\
\hline Higher & $\begin{array}{l}0.06 \\
(0.041)\end{array}$ & $\begin{array}{l}-0.08 \\
(0.038) *\end{array}$ & $\begin{array}{l}0.02 \\
(0.044)\end{array}$ & $\begin{array}{l}0.04 \\
(0.045)\end{array}$ & $\begin{array}{l}-0.15 \\
(0.039) \\
* *\end{array}$ & $\begin{array}{l}-0.25 \\
(0.046)^{* *}\end{array}$ & $\begin{array}{l}-0.09 \\
(0.043) \\
*\end{array}$ & $\begin{array}{l}-0.10 \\
(0.047) \\
*\end{array}$ \\
\hline $\begin{array}{l}\text { Multimorb } \\
\text { idity }^{d}\end{array}$ & $\begin{array}{l}0.11 \\
(0.052) \\
*\end{array}$ & $\begin{array}{l}0.02 \\
(0.048)\end{array}$ & $\begin{array}{l}0.02 \\
(0.057)\end{array}$ & $\begin{array}{l}0.05 \\
(0.058)\end{array}$ & $\begin{array}{l}-0.02 \\
(0.050)\end{array}$ & $\begin{array}{l}-0.05 \\
(0.059)\end{array}$ & $\begin{array}{l}0.00 \\
(0.055)\end{array}$ & $\begin{array}{l}-0.01 \\
(0.061)\end{array}$ \\
\hline $\mathrm{R}^{2}$ & $13 \%$ & $13 \%$ & $10 \%$ & $8 \%$ & $7 \%$ & $12 \%$ & $4 \%$ & $3 \%$ \\
\hline
\end{tabular}

*Significant at $\mathrm{p}<0.05, * *$ significant at $\mathrm{p}<0.01$

${ }^{a}$ Reference group: people who do not have that specific type of chronic illness. For example, people with COPD were compared with people who have another chronic disease(s)

${ }^{\mathrm{b}}$ Reference group: male

${ }^{\mathrm{c}}$ Reference group: people with lower educational level

${ }^{\mathrm{d}}$ Reference group: people with one chronic disease 


\section{ESM 1: PAST Questionnaire}

How often do you have to.... (1=never, 2 = sometimes, $3=$ mostly, $4=$ always $)$

And how often do you need (extra) support with these tasks? (1= never, $2=$ sometimes, $3=$ mostly, $4=$ always) Support can be seen as help from a health-care provider but also from a family or friends.

1. Cope with pain or limitations (Cp)

2. Take medicines as prescribed for you (M)

3. Visit doctors and other healthcare providers $(\mathrm{Cm})$

4. Take care of what you eat (L)

5. Exercise sufficiently (L)

6. Live a healthy lifestyle (stop smoking, not much alcohol) (L)

7. Cope with the limited amount of energy you have (Cp)

8. Cope with emotions and stress (Cp)

9. Ask for help if needed $(\mathrm{Cm})$

10. Abandon unhealthy habits (L)

11. Do exercises at home (M)

12. Use technical aids (M)

13. Understand the information of doctors and other healthcare providers $(\mathrm{Cm})$

14. Cope with limitations in, for example, going out, going on holiday, etc. (Cp)

15. Monitor your complaints and symptoms yourself (M)

16. Perform self-care tasks, like taking care of wounds, putting on elasticated stockings, taking your medicines (M)

17. Monitor your own health by, for example, monitoring your glucose or blood pressure (M)

18. Contact and talk with healthcare providers $(\mathrm{Cm})$

19. Cope with an uncertain future (Cp)

$\mathrm{M} \quad=$ Medical management

$\mathrm{Cm}=$ Communication with healthcare providers

$\mathrm{Cp} \quad=$ Coping with consequences

$\mathrm{L} \quad=$ Making lifestyle changes 
ESM 2: Explorative factor analysis of PAST questionnaire

An exploratory factor analysis using principal component extraction with varimax rotation was conducted to examine the factor structure of the PAST questionnaire. In this analysis, a four factor solution was given (Table 5). Values of the items should be at least .40 on one factor and lower than .35 on the other factors to be included in a particular factor. Based on this rule of thumb, the first factor consists merely out of items we considerate as coping (items 1, 7, 9, 1214 and 19). The second factor was less clear. Only item 17 clearly loaded on this factor. The third factor we considered a lifestyle factor (items 5, 6 and 10) and the fourth factor a medical factor (items 2, 15 and 16). The items that we considered as communication related loaded on more than one factor. This might be explained by the fact that communication is the basis for medical management, coping and making lifestyle changes.

Table 5: Explorative factor analysis of the PAST questionnaire (all items)

\begin{tabular}{l|llll}
\hline Variable & Factor $\mathbf{1}$ & Factor $\mathbf{2}$ & Factor $\mathbf{3}$ & Factor $\mathbf{4}$ \\
\hline Coping with the consequences & & & & \\
1. Cope with pain or limitations & .7765 & .0249 & .0631 & .1372 \\
7. Cope with the limited amount of energy you have & .7695 & .0670 & .1910 & .1523 \\
8. Cope with emotions and stress & .5422 & .1259 & .1947 & .0182 \\
14. Cope with limitations in, for example, going out, going on & .7686 & .0999 & .0511 & .1309 \\
$\quad$ holiday & & & & \\
19. Cope with an uncertain future & .6866 & .1635 & .0950 & .1922 \\
Making lifestyle changes & & & & \\
4. Take care of what you eat & .1402 & .5334 & .4118 & .0986 \\
5. Exercise sufficiently &. .0128 & .0272 & .7256 & .1836 \\
6. Live a healthy lifestyle (stop smoking, not much alcohol) & .1198 & .0111 & .7320 & .1226 \\
10. Abandon unhealthy habits & .2373 & .2768 & .5428 & -.1333 \\
Medical management & & & & \\
2. Take medicines as prescribed for you & .0700 & .1738 & .1504 & .7192 \\
11. Do exercises at home & .4132 & .2551 & .3552 & -.1307 \\
12. Use technical aids & .6314 & .1658 & -.0878 & .0327 \\
15. Monitor your complaints and symptoms yourself & .3295 & .0925 & .2954 & .4792 \\
Communication with healthcare providers & & & & \\
3. Visit doctors and other healthcare providers & .3455 & .4539 & .0954 & .2885 \\
9. Ask for help if needed & .6211 & .3392 & .0533 & -.0975 \\
13. Understand the information of doctors and other healthcare & .3467 & .4249 & .2473 & .1591 \\
$\quad$ providers & & & & \\
18. Contact and talk with healthcare providers & .3867 & .5917 & -.0945 & .1758 \\
\hline
\end{tabular}

Therefore, a second exploratory principal components analysis was conducted, leaving out the items that we considered as communication with healthcare providers. Then we found a three factor solution (Table 6). This solution corresponded with our theoretical framework, with the exception of 
item 12 and item 11. Item 12 refers to the use of technical aids, such as an inhaler or blood pressure pump. Only a small fraction of the population of people with chronic illness use such technical aids $(<10 \%)$, therefore we decided to delete this item (also in the final confirmatory factor analysis described in the manuscript). Item 11 refers to doing exercises at home and had a low factor loading on all three factors. We consider item 11 to refer to medical management (assuming that patients do exercises at home - like they take medication - as part of their treatment; for instance, as advised by a medical doctor or physiotherapist), but it could be argued that item 11 fits one of the other factors as well (for instance, when doing exercises is considered by the patient as healthy behaviour (lifestyle) or a way to reduce stress (coping).

Table 6: Explorative factor analysis of the PAST questionnaire (without communication related items)

\begin{tabular}{l|ccc}
\hline Variable & Factor 1 & Factor $\mathbf{2}$ & Factor 3 \\
\hline Coping with the consequences & & & \\
1. Cope with pain or limitations & .7867 & .0408 & .1148 \\
7. Cope with the limited amount of energy you have & .7749 & .1853 & .1297 \\
8. Cope with emotions and stress & .5457 & .2437 & .0313 \\
14. Cope with limitations in, for example, going out, going on holiday & .7866 & .0489 & .1264 \\
19. Cope with an uncertain future & .7035 & .1360 & .1863 \\
Making lifestyle changes & & & \\
4. Take care of what you eat & .2063 & .5066 & .3421 \\
5. Exercise sufficiently & -.0285 & .6942 & .1496 \\
6. Live a healthy lifestyle (stop smoking, not much alcohol) & .0879 & .7022 & .0774 \\
10. Abandon unhealthy habits & .2444 & .6030 & -.0034 \\
Medical management & & & \\
2. Take medicines as prescribed for you & .0767 & .1184 & .7121 \\
11. Do exercises at home & .4450 & .4059 & -.0351 \\
12. Use technical aids & .6642 & -.0721 & .0948 \\
15. Monitor your complaints and symptoms yourself & .3128 & .2726 & .4567 \\
16. Perform self-care tasks, like taking care of wounds, putting on & .2107 & .0003 & .5082 \\
$\quad$ elasticated stockings, taking your medicines & & & \\
17. Monitor your own health by, for example, monitoring your glucose & .1193 & .2128 & .5371 \\
$\quad$ or blood pressure & & & \\
\hline
\end{tabular}

